\title{
Analysis of Pap Smear Database in a Community Hospital
}

\author{
Sharma $\mathbf{R}^{1}$, Baral GN² , Dangal $\mathbf{G}^{\mathbf{1}}$ \\ ${ }^{1}$ Helping Hands Community Hospital, Kathmandu, Nepal, ${ }^{2}$ Paropakar Maternity and Women's Hospital, Kathmandu, \\ Nepal.
}

\begin{abstract}
Aims: This study was done to find out age wise distribution pattern, cellular abnormality and adequacy of Pap smears.
Methods: A retrospective study of 4800 Pap smears based on laboratory database was done from 2008 to 2011 at Helping Hands Community Hospital in Kathmandu, Nepal. Graphical method was used for normality test and frequency analysis was done using SPSS 16.

Results: Out of 4794 analysable data $4.21 \%$ had abnormal cytology, all high-grade lesions were in 51-65 age group and $0.06 \%$ were detected as carcinoma. Age group of 30-65 years covers four-fifth of the samples $(3811,79.4 \%)$ and $85.6 \%$ of abnormal cytology (173 out of 202 ) with maximum samples $(3313,69 \%)$ at $30-50$ years and $55.44 \%$ of abnormal cytology. Only $5.4 \%$ of samples categorized as inadequate by Bethesda reporting system. Age wise distribution of samples produced near normal Gaussian curve.
\end{abstract}

Conclusions: Pap samples were normally distributed by age. Test requisition forms lack adequate clinical information. Even the inadequately sampled Pap smears were satisfactory for evaluation.

Keywords: cancer, cervix, database, Pap, screening.

\section{INTRODUCTION}

Cancer of the cervix uteri is a preventable cancer and the third most common cancer among women worldwide. According to ICO Information Centre on HPV and Cancer 2014, women at risk for cervical cancer (female population aged $\geq 15$ years) in Nepal is 9.65 million. Cervical cancer ranks as the first cause of female cancer in 15-44 age group (2,332/year) and of death in all age group (1367/year). ${ }^{1}$ At least $80 \%$ of cervical cancer deaths occur in developing countries, with most occurring in the poorest regions.

Pap smear is a well-recognized cervical cancer screening tool that can be reviewed and archived. The test done to detect precancerous lesions of the cervix is a very simple method. The simplicity of this test is because of the ease with which the cervix can be examined as well as the exfoliating cervical cells, which can easily be taken out by a spatula and made into smears and studied instantly. Hence, Pap smears are commonly used as cytological screening test for successful detection of precancerous lesions. Pap

\section{CORRESPONDENCE}

Dr Reetu Sharma

Department of Pathology, Helping Hands Community Hospital, Kathmandu, Nepal

Email: reetu.baral@gmail.com

Phone: +977-9841829242 smear examination has been a routine screening test for cervical cancer worldwide. It is a safe, reliable, affordable and accurate test, which helps in detecting pre-cancer stage while chance of cure is still good and hence can prevent death.

This study was conducted in a community hospital to study the age wise cellular abnormal pattern of Pap smears, adequacy of smears for cytological evaluation and the distribution of samples by age group.

\section{METHODS}

This is a retrospective study done in the Department of Pathology in Helping Hands Community Hospital, Kathmandu, Nepal. The study was conducted from 2008 to 2011. A total of 4800 pap smears were collected in this period. The pap smear specimens were collected by Gynecologists in Helping Hands Community Hospital, from Gynecology health camps and from private clinics run by Gynecologists. These specimens were received in the cytopathology laboratory in Helping Hands Community Hospital. Smears were collected by an Ayres spatula and cervical brush after exposing the cervix by a Cusco's speculum. The samples were gently smeared on prelabelled glass slides. The glass slides were fixed by mixture of equal amount of ether and $95 \%$ ethanol, and by fixating spray from out-reach camp. The 
slides were sent to the Cytopathology Laboratory. A cytotechnologist stained the slides with Papanicolaou stain. Each slide was then meticulously examined by pathologists. All the findings were recorded in the database and classified according to the 2001 Bethesda System of reporting Pap smear cytology. Graphical method of normality test is done to compare data distribution by age. Test requisition form without age of the patients were excluded. Analyzable data from cytopathology database were analysed using SPSS 16.0 version. Study approval was taken from the hospital.

\section{RESULTS}

A total of 4800 cases were studied between 2008 to 2011. Out of these six cases had to be excluded from the study due to lack of full information in the requisition form. In this study the age was grouped as per WHO recommendation for screening., ${ }^{2,3}$ The recommended screening age of 30-65 years consists of four-fifth $(3811,79.4 \%)$ of data and $85.6 \%$ (173 out of 202) of abnormal smears. Maximum number of cases (3313 cases or 69\%) was of age group 30-50 years followed by the age group of 21-29 years with a total number of 903 or $18.8 \%$. The least were below the age of 21 with 36 cases or $0.8 \%$ only. Patients between the age of 51-65 comprised 498 cases or $10.4 \%$ and that above 65 years of age were only 44 cases or $0.9 \%$. Thus the samples received from extremes of age were only $1.6 \%$. Both age and age group displayed a normal Gaussian curve in histogram showing normal distribution of data (Figure 1 and 2).

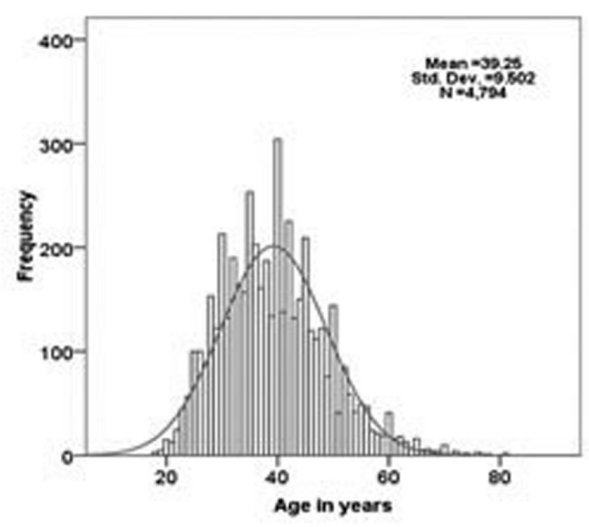

Figure 1. Histogram showing age-wise distribution $(n=4794)$.

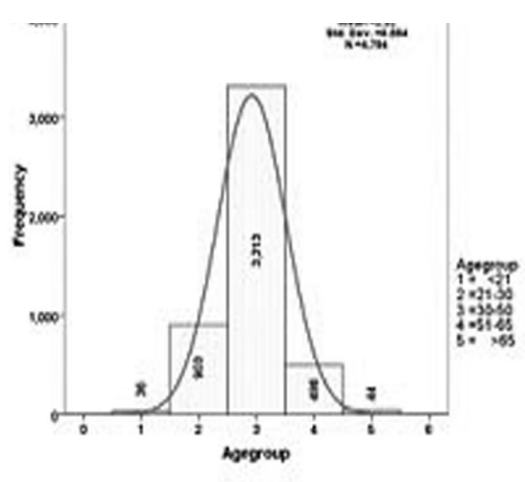

Figure 2. Histogram showing age group-wise distribution $(n=4794)$.

The negative for intraepithelial lesion or malignancy comprised the largest percentage with 4584 cases (95.6\%) followed by Atypical Squamous Cells of Undetermined Significance (ASCUS) at 158 cases (3.3\%), Low Grade Squamous Intraepithelial Lesion (LSIL) at 43 cases $(0.89 \%)$ and High Grade Squamous Intraepithelial Lesion (HSIL) at 6 cases $(0.12 \%)$ and carcinoma 3 cases $(0.06 \%)$. Three cases showed typical features of carcinoma including karyomegaly, coarse nuclear pattern and prominent nucleoli. Maximum number of ASCUS was seen in the age group of 30-50 years with a total of 85 cases followed by 53 cases in the age group of 51-65 years. ASCUS was negative in the age group of less than 21 years. Out of 43 cases of LSIL, 24 cases $(55.8 \%)$ were seen in the age group of 30-50 years. It was least in both the extremes of age group with only 1 case in below 21 years age group and 2 in above 65 age group. Total abnormal epithelial lesion was seen to be only $0.06 \%$. A total of 6 cases of HSIL was seen in the age group of 51-65 years. Frank carcinoma was seen in 3 cases and all belonged to the age group of 30-50 years (Table 1). 
Table 1. Age-wise distribution of abnormal finding in Pap smear.

\begin{tabular}{lllllll}
\hline $\begin{array}{l}\text { Age - } \\
\text { group } \\
\text { (years) }\end{array}$ & Freq. & \multicolumn{5}{c}{ Abnormal cytology } \\
\hline$<21$ & $\begin{array}{l}36 \\
(0.8 \%)\end{array}$ & 0 & 1 & 0 & 0 & 1 \\
& & & & & $(2.3 \%)$ \\
$21-29$ & $\begin{array}{l}903 \\
(18.8 \%)\end{array}$ & 16 & 6 & 0 & 0 & 22 \\
& & & & & $(2.4 \%)$ \\
$30-50$ & $\begin{array}{l}3313 \\
(69 \%)\end{array}$ & 85 & 24 & 0 & 3 & $\begin{array}{l}112 \\
(3.3 \%)\end{array}$ \\
$51-65$ & $\begin{array}{l}498 \\
(10.4 \%)\end{array}$ & 53 & 10 & 6 & 0 & 61 \\
$>65$ & $\begin{array}{l}44 \\
(0.9 \%)\end{array}$ & 4 & 2 & 0 & 0 & $\begin{array}{l}6 \\
(12.2 \%)\end{array}$ \\
Total & $\begin{array}{l}4794 \\
(100 \%)\end{array}$ & 158 & 43 & 6 & 3 & $\begin{array}{l}(13.6 \%) \\
(3.2 \%)\end{array}$ \\
& $(0.89 \%)$ & $(0.12 \%)$ & $(0.06 \%)$ & $(4.21 \%)$ \\
\hline
\end{tabular}

A total of 261 specimens (5.4\%) were limited by inadequate sampling but still found satisfactory for evaluation. In 115 (2.4\%) of these cases endocervical component was absent; 91 cases (1.9\%) showed dense inflammatory cells obscuring the squamous cells; haemorragic smear was seen in $46(1.0 \%)$; scant cellularity in $8(0.2 \%)$ and poor fixation of the slide was seen only in one case. Clinical information such as menstrual history, parity, treatment, contraception and pelvic examination findings were not available in most of the requisition forms. There were only 54 forms $(1.1 \%)$ with pelvic findings filled up. All slides were evaluated with comments on adequacy of sampling (Table 2).

Table 2. Limitations in adequacy of the Pap smear.

\begin{tabular}{lll}
\hline Reason for Limitation & Frequency & $\begin{array}{l}\text { Percentage } \\
(\%)\end{array}$ \\
\hline No endocervical component & 115 & 2.4 \\
Obscuring inflammatory cells & 91 & 1.9 \\
Obscuring RBCs & 46 & 1 \\
Scant cellularity & 8 & 0.2 \\
Poor fixation & 1 & 0.02 \\
Total & 261 & 5.4 \\
\hline
\end{tabular}

Most of the reports (75.4\%) were ready by next day with mean reporting days of 1.55 and $88.3 \%$ of reports were prepared in two days of receipt of slide in lab. Only $4 \%$ of slides, which were received, from outreach screening camps were completed in a week. Same day reporting was possible in $1.4 \%$ of cases (Table 3).
Table 3. Pap smear reporting time in days $(n=4559)$.

\begin{tabular}{llll}
\hline $\begin{array}{l}\text { Days since } \\
\text { receipt of slide }\end{array}$ & Frequency & Percent & $\begin{array}{l}\text { Cumulative } \\
\text { Percent }\end{array}$ \\
\hline 0 & 66 & 1.4 & 1.4 \\
1 & 3371 & 73.9 & 75.4 \\
2 & 589 & 12.9 & 88.3 \\
3 & 170 & 3.7 & 92.0 \\
4 & 85 & 1.9 & 93.9 \\
5 & 95 & 2.1 & 96.0 \\
6 & 120 & 2.6 & 98.6 \\
7 & 28 & 0.6 & 99.2 \\
8 & 35 & 0.8 & 100.0 \\
\hline
\end{tabular}

\section{DISCUSSION}

Age group has been binned according to the age recommended by WHO for the screening of cervical cancer such as 30 years to start for low risk ( 25 for high risk) population till 65 years of age at 3 years interval below 50 years and every 5 years thereafter; and in between 35 and 45 if a woman has to be screened only once in her life time. ${ }^{2,3}$

The Papanicolaou or Pap smear test for cervical cancer has saved thousands of lives since it was introduced in the early 1940s. Deaths from cervical cancer have decreased by more than $70 \%$ over the last 50 years during which the screening test has been widely used. In the USA, mortality rates have declined in the past decades due to prevention and early detection as a result of screening with Pap test. ${ }^{4}$ Pap smear is the routine test done for screening of cervical cancer all over the world. In the developing nations advantage of cervical cytology are the simplicity and low cost while the disadvantages are unavailability of electricity, reagents and other supplies. ${ }^{5}$

Cervical carcinoma does not develop suddenly from normal epithelium but is presented by a spectrum of intraepithelial changes, which are precancerous lesion. In a previously unscreened population of women aged between 25 and 65 years, the following percentages of abnormal results are likely: LSIL $3-10 \%$, HSIL $1-5 \%$ and invasive cancer $0.2-0.5 \%{ }^{2}$ These findings are similar to the findings in our study.

In this study the abnormal smears were seen mainly among the age group more than 21 and less than 65 years of age. In a study done by Pradhan ${ }^{6}$ in 800 samples, the abnormal smears were seen mainly among age group of 21-40 years and carcinoma was also found mainly in this group. In a study done by 
Pradhan et $\mathrm{al}^{7}$ in 200 samples, all of the women who had atypia, also had inflammation and were between 35 and 50 years of age, a risky age group for the development of CIN and cervical carcinoma. On analyzing 2288 Pap tests in a study done in a hospital in Nepal they had found precancerous and malignant lesions in 65 cases. These cases were analyzed by their age groups, which revealed similar proportion of abnormalities in between 26-35 years and 36-45 years of age group respectively. ${ }^{8}$ ASCUS was seen to be highest in the age group 31-50 years in a study of 1369 samples analysed by Hirachand et $\mathrm{al}^{9}$ in a tertiary centre in Kathmandu.As the age increases the incidence of epithelial abnormality also increases. This is also seen in 880 samples studied by Ranabhat et al, ${ }^{10}$ where $80 \%$ of all epithelial abnormality was seen in patients more than 40 years of age. Proportion of ASCUS (3.2\%) is similar to the report given in Evidence Based Medicine (4\% $)^{11}$ and Vaghela et al ${ }^{12}$ $(2.8 \%)$.

The diagnosis of ASCUS is important as it progresses to LSIL, HSIL and SCC. All six cases of HSIL were seen in the age group of 51-65 years, which is similar to the study done in 221 cases by Tirumalasetti et al. ${ }^{13}$ Cervical cancer is rare in women under 30 years of age and most common in women over 40 years, with the greatest number of deaths usually occurring in women in their 50 s and $60 \mathrm{~s} .{ }^{1}$ In a study done by Dangal et al ${ }^{14}$ in BP Koirala Memorial Cancer Hospital it is seen that the mean age of cervical carcinoma is 46 years that lies in the age group of 30-50 having diagnosis of carcinoma in current study.

When the Pap smear is interpreted the pathologist will have to mention about the adequacy and quality of the specimen. Bethesda system has developed the criteria for determining the adequacy and quality of the pap smears. According to the Bethesda system, the criteria includes estimations of number of squamous and endocervical cells present, specimen preservation and fixation and the absence of obscuring inflammation and blood. Based on these criteria, Pap smears have been categorised as: satisfactory, unsatisfactory or satisfactory but limited by. Patients with unsatisfactory smear usually undergo a repeat pap smear in a few months. But recommendations for the ones with satisfactory but limited by are less defined. It has been agreed upon that they should be rescreened in the same way as the ones with satisfactory smears. ${ }^{15}$
If the adequacy of the smear is limited by absence of endocervical cells, obscuring inflammation or blood, then screening has to be repeated after 12 months. The reason of receiving $5.4 \%(n=261)$ of the slides as inadequate could be due to opportunistic screening, however, these were evaluated as satisfactory not requiring immediate re-sampling (Table 2). Early repeat can be done if previous ASCUS was seen, unexplained glandular abnormality, positive for high risk HPV, immunocompromised patient, clinician not able to visualize the cervix or sample the endocervical canal, similar obscuring factor in the previous pap test and insufficient previous screening. ${ }^{16}$

According to the most recent WHO data, only $4.7 \%$ of women had cost coverage for cervical cancer screening in urban areas and $2.0 \%$ in rural areas, averaging $2.4 \%$ in the country $(\mathrm{WHO} / \mathrm{ICO}$, 2010). However, there were no reported data on the percentage of women actually screened. ${ }^{17}$ In a developing country like Nepal where statistics show a high rate of cervical cancer mortality, suitable methods for detection of cervical cancer has to be implemented. Pap smear is the single most successful objective cancer screening tool in modern medicine, which is simple, cheap, safe, and practical diagnostic tool for early detection of pre-cancerous lesion in the cervix where cytodiagnostic facility exists. The average reporting time since receipt of slides is one day in majority of samples except those received from outreach screening camps.

\section{CONCLUSIONS}

The current study sample yields a statistical normal curve reflecting content validity with modal value 3313 at 30 to 50 years age group. This age group corresponds with the WHO recommendation of cervical cancer screening. Cervical carcinoma was detected in $0.06 \%$ of Pap specimens from $4.21 \%$ of abnormal cytology. There is gross inadequacy of clinical information in Pap requisition form and $5.4 \%$ of specimens were not adequately sampled but still satisfactory for evaluation. This study recommends clinicians to provide information on pelvic examination findings in test requisition form as well as adequate sampling to include endocervical cells in Pap smear. 


\section{DISCLOSURE}

The authors report no conflicts of interest in this work.

No violation of human rights and safety.

Funding: Nil

\section{REFERENCES}

1. Bruni L, Barrionuevo-Rosas L, Serrano B, Brotons M, Cosano R, Muñoz J, et al. ICO Information Centre on HPV and Cancer (HPV Information Centre). Human Papillomavirus and Related Diseases in Nepal. Summary Report 2014-03-17. [Data Accessed]

2. World Health Organization. Comprehensive cervical cancer control: a guide to essential practice. Geneva: WHO; 2006.

3. Baral G. Managing cervical cancer in Nepal: need of consensual guideline. NJOG. 2009;4(1),3-10.

4. American Cancer Society. Cancer facts and figures 2014. [Cited on 2014-06-01]. Available from: http://www. cancer.org/acs/groups/content/@research/documents/ webcontent/acspc-042151.pdf

5. Tambouret R. Screening for cervical cancer in low-resource settings in 2011. Arch Pathol Lab Med. 2013;137:782-90.

6. Pradhan P. Prevention of carcinoma of cervix: role of Pap smear screening. Nepal Med Coll J. 2003;5(2):82-6.

7. Pradhan N, Giri K, Rana A. Cervical cytological study in unhealthy and healthy looking cervix. NJOG. 2007;2(2): 42-7.

8. Ghosh A, Rao S, Pramanik T. Is it relevant to screen women younger than 26 years for pre-cancerous and malignant cervical lesions? APJCP. 2005;6.

9. Hirachand S, Bajracharya J, Pradhanang S, Lama S Detection of abnormal cervical cytology in Papanicolaou smears in a tertiary care center. J Nepal Med Assoc. 2013;52(191):462-5.

10. Ranabhat SK, Shrestha R, Tiwari M. Analysis of abnormal epithelial lesions in cervical Pap smears in Mid-western Nepal. JPN. 2011;1:30-3.

11. Lappe J, Gossett DR. Evidence-based cervical cancer screening: the modern evolution of the Pap smear. In: Nikolaos MS, editor. Evidence Based Medicine - Closer to Patients or Scientists. 2012. ISBN 978-953-51-0504-6. Available from: http://www.intechopen.com

12. Vaghela BK, Vaghela VK, Santwani PM. Analysis of abnormal cervical cytology in Papanicolaou smears at tertiary care center: a retrospective study. International Journal of Biomedical and Advance Research. ISSN: 2229-3809 (Online).

13. Tirumalasetti N, Navyaa VR. IJPRBS, 2012; Volume 1(5): 379-389. ISSN: 2277-8713.

14. Dangal G. Initial experience of radical hysterectomy for early cervical cancer at a cancer hospital in Nepal. JNMA. 2004;43(156):297-302.

15. Adams AL, Gidley J, Roberson J, Wang W, Eltoum I, Chhieng DC. Clinical significance of unsatisfactory conventional pap smears owing to inadequate squamous cellularity defined by the Bethesda 2001 criterion. Am J Clin Pathol. 2005;123:738-43.
16. Davey DD, Austin RM, Birdsong G, Buck HW, Cox JT, Darragh TM, et al. ASCCP Patient Management Guidelines, Pap Test Specimen Adequacy and Quality Indicators. Am J Clin Pathol. 2002;118:714-718.

17. Satyal K. Cervical cancer screening behavior among Nepalese women [PhD thesis]. George Mason University; 2013. 